\section{FORMAR PARA EL ACOMPAÑAMIENTO ESPIRITUAL VOCACIONAL}

Autora: $M^{a}$ Luz Galván, religiosa de la Sociedad del Sagrado Corazón de Jesús, Secretaria general de CONFER.
Importante para crecer en el camino de la fe, el acompañamiento, tras el abandono de toda dirección espiritual posterior al Vaticano II. Desde la amistad, exigiendo un sentido contemplativo. Respetando la libertad y sus peculiaridades como persona, su motivación profunda y su compromiso real con el entorno. Del acompañante se exige madurez, persona integradora de los aspectos diferentes de la personalidad del acompañado; que se mueva desde el amor y sea persona esperanzada, que entre en una relación de empatía e imite el modo de acompañar de Jesús.

DOI: https://doi.org/10.52039/seminarios.v47i161.951

\title{
Introducción
}

Crecer en el caminar de la fe es desde siempre el desafío que se presenta al cristiano a lo largo de su vida, desde el momento de su Bautismo, y especialmente desde que el uso de razón comienza a liberar su libertad.

Como hijos e hijas de Dios hemos recibido todos en germen toda la plenitud de Dios y a ella nos hemos de encaminar. Pero esto es tarea sencilla aunque no fácil porque ha de ser vivida en medio de la complejidad de todo lo humano. Por ello el cristiano que se ha planteado con cierta seriedad su vida cristiana siempre ha necesitado de mediaciones personales que le ayuden a orientarse en el bosque complejo de la propia interioridad y contribuyan a verificar la verdad de su discernimiento de las llamadas de Dios experimentadas en su corazón a lo largo y a lo ancho del encuentro con la vida.

Este papel de mediación orientadora tradicionalmente se confiaba al director espiritual, una persona con cierta "ancianidad espiritual", 
un experto en los caminos de Dios. Era una figura clave a la hora de recibir confidencias íntimas, a la hora de discernir caminos y de ayudar a adoptar posturas. La mediación del director espiritual indicaba en muchos casos y aseguraba en otros la correcta orientación de las propias opciones.

Cuestiones en las que no voy a entrar ahora hicieron que la figura de Director espiritual se hiciera demasiado directiva, sea por tendencia innata del propio director a ser decisionista o por especial autocomprensión de su papel, sea por la excesiva docilidad, o por el abandono de la propia responsabilidad por parte de la persona dirigida. $\mathrm{O}$ sencillamente porque vivíamos dentro de una sociedad autocrática.

Esta era la situación previa a la revolución pastoral copernicana que supuso el Concilio Vaticano II. No dijo éste nada especial referido al papel de los directores espirituales, pero sí dio un impulso a la madurez y libertad de la persona y al diálogo con la sociedad moderna. La iglesia hubo de ponerse en contacto con las corrientes de la sociedad que hablaban de tolerancia y democracia que fortalecían el crecimiento de la libertad personal y autonomía responsable de los individuos, se abrió también a las críticas a la experiencia religiosa que le venían desde las ciencias humanas. Como resultado de todo esto la teología vivió un proceso profundo de reformulación. La Psicología y

La revoluAntropología teológicas quedaron profundamente afectadas por las ción pastoral del Vaticano II hizo tambalearse la figura del director espiritual aportaciones de estas ciencias humanas y hubieron de remodelarse. Sin entrar en más detalles que ahora no hacen al caso, digamos que, como resultado de un complejo proceso, la figura del director espiritual cayó en picado. De hecho la figura del director sufrió una profunda convulsión. Muy pocos directores se atrevieron a seguir ejerciendo esta manera de paternidad espiritual y muchos, la mayor parte de los dirigidos, abandonaron en su propia vida la dirección que se consideraba hasta entonces una práctica saludable de vida espiritual, y un instrumento indispensable de progreso espiritual. También en las Órdenes y Congregaciones se dieron los avatares de este proceso. Quizá fue una etapa de depuración necesaria, como tantas otras depuraciones que ha sufrido la Iglesia en su caminar.

Hoy, viendo ya las cosas con otra perspectiva, podemos darnos cuenta de que esta ausencia de dirección y compañía, no se notó en los primeros años de entusiasmo conciliar. Estábamos todos los cristianos 
demasiado interesados en proyectos, en cambios de tantas estructuras y en el intento de abrir nuevos caminos que no quedaba lugar para verificar si el debilitamiento de la dirección espiritual había supuesto una pérdida real para la vida cristiana. Se vivía de un impulso fuertemente creativo y activo.

Pero ya han pasado muchos años desde este profundo vuelco. Treinta y cinco años después nos encontramos en una situación muy diversa. El impulso renovacionista ha decaído. Se han alcanzado muchas metas del cambio y hay muchos nuevos caminos no sólo abiertos sino recorridos largamente. Todos tenemos la impresión de que hemos avanzado en muchos ámbitos pero que hemos llegado a un punto en el que estamos en tiempos de tocar fondo, o de avanzar hacia la raíz. Me parece que reconocer esto es bien importante, porque hacia adentro y hacia abajo no se puede avanzar solo tan fácilmente. La cuestión de la dirección espiritual reaparece de nuevo, primeramente con cierta timidez, ahora mismo ya con cierta fuerza, como necesidad sentida aunque con matices diversos. No tiene los tonos puramente intimistas de antaño, ni sus connotaciones individualistas que quizá tuvo en exceso. Surge como necesidad para el cristiano en su caminar en relación con Dios, con los demás y dentro del mundo que lo rodea.

La comunidad cristiana lleva una existencia mucho más frágil que antaño en medio de una sociedad neopagana. Su situación se asemeja mucho a la de los orígenes, pero hoy parece tener la característica de vivir en medio de una sociedad que ya ha oído hablar del Dios de Jesucristo y tiene muchos anticuerpos relacionados con ello.

Muchos cristianos se encuentran muy desorientados en lo que a su vida cristiana y espiritual se refiere. La sociedad que vivimos es tan plural, las cuestiones se han hecho tan nuevas que crece la experiencia frustrante de no encontrar fácilmente un camino coherente. El cristianismo en Occidente ha dejado de ser un ámbito confortador de opinión pública. El cristiano tiene que serlo valientemente "a pesar de la sociedad" y se siente muy solo y en ambiente muchas veces indiferente si no hostil a la vida cristiana.

Por otra parte un nuevo deseo religioso brota en el fondo del corazón de los creyentes, se siente la necesidad de vivir la propia fe de manera profunda y coherente, y hay un deseo de encuentro con el Dios vivo. Se hace muy necesario el discernimiento.

Ahora la necesidad de dirección espiritual aparece con

fuerza

Necesidad del discernimiento 
Dios se sirve de todos los caminos para ayudar a sus hijos. Todas estas circunstancias hacen que se plantee de nuevo la necesidad de la compañía cristiana, del acompañamiento espiritual. Se empieza a vislumbrar una nueva necesidad de ser acompañados en el propio proceso de la fe. Resulta muy difícil, por no decir imposible aventurarse en la aventura cristiana, que es más que nunca una aventura de profundidad, sin alguien que sostenga, que guíe, que fortalezca y acompañe las Lafigura propias convicciones. Surge así la necesidad de un proceso de acompastoral del acompañamiento pañamiento, y se perfila de nuevo la figura del acompañante. No es ya como la del director espiritual alguien que es una figura paterna y autoritativa, sino que tiene características distintas al anterior modelo, es más fraterna, profundamente respetuosa de la libertad del sujeto y brota como una nueva figura pastoral esencial al tiempo que vivimos y a las necesidades que hoy tiene la iglesia.

No existen aún entre nosotros muchas personas experimentadas en el arte de acompañar. Esta nueva manera de ser mediación requiere nuevos aprendizajes. La experiencia espiritual a acompañar será siempre la misma: el itinerario del hombre hacia Dios. En este sentido bien puede nutrirse en lo esencial del bagaje pasado, del tesoro que los verdaderos ancianos espirituales acumularon de sabiduría espiritual. Pero las condiciones de la vida moderna, la situación del hombre en él, el cambio establecido en las relaciones humanas ha hecho que se necesite y se haya de dar importancia a nuevas dimensiones Por ello se hace Crear necesario crear ámbitos de formación que posibiliten el resurgimiento ámbitos de formación y el apoyo a esta nueva figura que en la situación que vivimos se va a hacer cada vez más y más indispensable. Estamos ahora a tiempo de recrear esta figura del acompañante.

Entraremos en el tema que se me ha planteado ordenadamente y cuidando la perspectiva. Para ello nos preguntaremos primeramente por la comprensión de la vida misma.

\section{La vocación a la vida y la vida como vocación}

Reconocer que la vida es un don es el primer paso que ha de dar el creyente. Un paso que nos remite al Creador y nos invita a agradecer su regalo con la realización de una vida digna de acuerdo con el don recibido. Esta es una convicción que nos impulsa a trabajar en la 
Iglesia para que cada persona llegue a conocer su vida como don, su propio don, su original y peculiar don. "Toda persona, sin excluir a ninguna, es un don original de Dios que espera ser descubierto" 1. La vida es un don, y cada persona un don original. Por ello la persona humana ha de hacerse disponible para acogerlo en gratuidad, tal como se le da, y ha de abrirse a irlo descubriendo en toda su riqueza a lo largo de la vida. Descubrir la originalidad de ese don y llegar a acogerlo es una tarea. Supone en toda persona una vocación íntima que le llama a vivirlo en plenitud. Todo hombre, toda mujer tiene una vocación, un llamada a la vida que ha de descubrir.

Hace cuatro años tuvo lugar en Roma un acontecimiento de importancia para la Iglesia Europea: el congreso Europeo de las Vocaciones consagradas. Su documento conclusivo es enormemente interesante y plantea no sólo los principales desafíos que hemos de afrontar hoy en la pastoral vocacional, sino que ofrece interesantes y pedagógicos caminos de respuesta.

En este documento se habla constantemente de la vocación pero no se considera ésta reducida a un momento determinado de la vida, en el que la vocación está considerada como una llamada particular especial tan sólo. El documento plantea que la vida misma es toda ella una vocación desde el momento que hombres y mujeres hemos sido llamados a la vida.

La vida es vocación. Todo hombre y mujer está llamado a realizar en su vida el sueño de Dios, el proyecto para el que ha sido originalmente creado y puesto en esta mundo. Todo las personas tenemos un lugar en este mundo, tenemos una misión original que cumplir, los creyentes tenemos un ministerio eclesial, que nos está preparado. Dios nos ha otorgado el don de la vida y con ella la llamada a vivirla como un don y a cultivar las facetas de la vida que nos hacen progresar hasta la plenitud de la vocación a la que hemos sido convocados.

Tenemos necesidad como afirma el documento a elaborar una verdadera "cultura de la vocación". Un ambiente en el que cada persona se sienta llamada a realizar su propio proyecto de vida en respuesta a una llamada recibida que ha de descubrir progresivamente y que habrá de cuajar, cuando llegue la época apropiada en una vocación par-

${ }^{1}$ Nuevas vocaciones para una nueva Europa. $13 \mathrm{c}$.

Hacernos disponibles para acoger la vida como don

\section{como don}

Toda persona está llamada a realizar en su vida el sueño de Dios sobre él

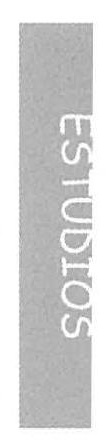


ticular o forma específica de vida. Toda la comunidad cristiana debe estar concebida girando en torno a este eje de la vocación. La vocación dura toda la vida por tanto será necesario contar con una ayuda que a lo largo de la vida nos permita ir identificando los pasos progresivos por los que ha de discurrir la propia vocación. La comunidad ha de acompañar este proceso vocacional de niños, jóvenes y adultos hasta la última etapa de la vida. Y esto de muchas maneras. Con el calor de la propia comunidad y con la mediación de personas concretas que entrando en una relación más personal permitan a la persona abrirse en sus círculos íntimos de manera que la acción mediadora de acompañamiento pueda ser más eficaz.

Hemos establecido con esto que la vida entera es una vocación y

Acompañamiento, ayuda que dura toda la vida, específico en cada etapa que por tanto, cuando hablamos de acompañamiento vocacional no debemos restringirlo exclusivamente al acompañamiento que hacemos de los jóvenes para fortalecer la búsqueda de una determinada vocación específica. El acompañamiento es una ayuda que hemos de recibir los cristianos de parte de la iglesia a lo largo de toda la vida y que nos ayuda a descubrir progresivamente nuestra vocación y a vivirla en plenitud. Evidentemente hay etapas de la vida que requieren un acompañamiento específico, o mejor dicho una forma específica de acompañamiento tendente a ayudar a verificar la opción de vida. Hay que decir que el acompañamiento en esta etapa es un requisito absolutamente indispensable. Pero en realidad el acompañamiento en lo que yo creo es un don que nos debiéramos otorgar en la Iglesia unos a otros a lo largo de toda la vida.

\section{Acompañamiento espiritual}

Precisemos algo más. Si hablamos de acompañamiento espiritual se hace necesario decir lo siguiente. No estamos solos en la vida humana por más que tantas veces al hombre y a la mujer se le haga dura y pesada la soledad. Dios nos acompaña a lo largo de todo el caminar y nos sale constantemente al encuentro. Lo sabemos por la fe, pero si ahondamos descubrimos que Él camina con nosotros. "Todas nuestras sendas te son familiares" dice el s. 139. Todo hombre y mujer tiene un acompañamiento interior fundamental que le ha dejado Jesús para sostenerle y guiarle en la propia vida. Este acompañamiento es el que rea- 
liza en nuestras vidas, en su nombre, el Espíritu Santo. Él es el Maestro interior que indica el camino, que sugiere pasos y respuestas, que sostiene en la oscuridad inevitable, que conforta en las luchas. La preciosa secuencia del Espíritu Santo expresa en forma de súplica su acción multiforme en la persona del creyente.

\author{
Ven, Espíritu divino \\ Manda tu luz desde el cielo. \\ Padre amoroso del Pobre, \\ Don en tus dones espléndido \\ Luz que penetra las almas \\ Fuente del mayor consuelo \\ Ven dulce huésped del alma \\ Descanso de nuestro esfuerzo \\ Tregua en el duro trabajo \\ Brisa en las horas de fuego \\ Gozo que enjuga las lágrimas \\ y reconforta en los duelos \\ Entra hasta el fondo del alma, \\ Divina luz, y enriquécenos \\ Mira el vacío del hombre.
}

\author{
Si tú le faltas por dentro \\ Mira el poder del pecado, \\ cuando no envías tu aliento \\ Riega la tierra en sequía \\ Sana el corazón enfermo \\ Lava las manchas, infunde \\ calor de vida en el hielo \\ Doma al espíritu indómito, \\ Guía al que tuerce el sendero, \\ Reparte tus siete dones \\ Según la fe de tus siervos \\ Por tu bondad y tu gracia \\ Dale al esfuerzo su mérito \\ Salva al que busca salvarse \\ $\mathrm{y}$ danos tu gozo eterno
}

Sin una atención a la acción del Espíritu, no hay posibilidad de hacer un itinerario cristiano. Sin ello, por parte de la persona que acompaña y sobre todo de quien es acompañado, no tiene sentido el acompañamiento. $\mathrm{O}$ dicho de forma positiva. Toda persona que acompaña se ha de convertir sobre todo en una persona que escucha, que está atenta a las mínimas insinuaciones del Espíritu en el acompañado, y su labor es por esta razón, aunque importante, secundaria: se trata de secundar al Maestro interior que señala el camino, indica las etapas, sugiere el paso o la acción a realizar. Se trata de ayudar al acompañado en la escucha de ese mismo Espíritu. Es un modo de reflejarle la luz que él mismo recibe, de fortalecerle y confirmarle en los movimientos y mociones que vienen del mismo Espíritu, de devolverle a su propio corazón para que él mismo sea una persona de escucha y respuesta.

En una palabra, se trata de secundar la acción del mismo Espíritu, en la persona del acompañado, acción que no se protagoniza sino que es ulterior a la iniciativa que viene de Él. Esta acción del Espíritu

Toda persona que acompaña ha de ser una persona que escucha 
es permanente pero muy delicada, porque Dios no se impone al creyente. Por ello necesitamos de una verdadera actitud de escucha.

No quiere decir esto que sólo el ámbito "espiritual" sea el objeto

Acompañamiento a partir de toda la realidad de la vida del acompañamiento. El Espíritu anima y acompaña el camino de la persona en todo lo que ésta es. El acompañamiento del maestro interior es un acompañamiento espiritual integral, que sigue y acompaña a la persona en todos los ámbitos y facetas de su propia vida. Por ello una persona que asume la función de acompañar ha de estar atenta a todos los aspectos de la vida de su acompañado porque es a partir de toda la realidad y en el seno de ella como la persona crece. Dios no desprecia la carne puesto que es Él mismo quien la ha creado y la ha puesto en el mundo. Son todos los ámbitos que contribuyen a que la persona sea lo que es y esté donde está los que habrán de tenerse en cuenta en un verdadero acompañamiento espiritual.

\section{Acompañamiento}

Otro aspecto importante que hemos de tener en cuenta es que el papel del que acompaña es también secundario desde otro punto de vista. La responsabilidad de la persona que es acompañada en su respuesta a Dios es algo absolutamente primario y esencial.

La libertad del acompañado para optar, para caminar, para plantear los caminos es indispensable. El verdadero protagonista en la vida es la propia e insustituible libertad interior de la persona que quiere comprometerse o no en el camino de la vida. El papel del acompañante será la de fortalecer lo mejor de esa libertad, sostenerla cuando vacile, iluminarla cuando se oscurezca, confortarla cuando experimente la fragilidad. Como ya he dicho más arriba esto supone una actitud verdaderamente contemplativa, una actitud de escucha atenta, insisto, por parte del que acompaña que habrá de descubrir en todo momento por

Nunca se puede suplantar la libertad del que camina dónde el Espíritu, que es el verdaderamente respetuoso de la libertad de los hijos de Dios indica el camino a seguir para no suplantar en ningún momento la libre respuesta del que avanza por el camino de la propia vida y vocación. Por ello el acompañante ha de suscitar libertad y fortalecer la autonomía de aquél a quien acompaña, de manera que éste se haga cada vez más responsable de su propio caminar. 


\section{IV Ámbitos del acompañamiento espiritual}

No pretendo ser exhaustiva enumerando todos los aspectos que han de ser tomados en consideración por las personas que acompañan, pero sí señalar los aspectos que me parecen fundamentales.

\section{La personalidad del acompañado}

Estamos ante un sujeto humano, que tiene unas bases psicológicas, un temperamento, un proceso de maduración, unas relaciones familiares básicas, una historia. Todo este conjunto determina su personalidad. Todo el caminar del sujeto acompañado va a estar muy mediado por estos aspectos de su persona, en el que inciden muchos factores. Tratar de conocerle en ello, se hace una necesidad básica para la persona que acompaña. Y esto de manera especial cuando la persona que acompañamos está aun en una etapa de maduración juvenil. Estudiar sus relaciones, su lenguaje, su capacidad de encuentro consigo mismo y con los demás, su coherencia y consistencia personal es indispensable. No quiere decir esto que la persona que acompaña sea un experto en psicología pero sí que hay ciertas bases psicológicas de la persona que se deben conocer para saber situar los datos que se reciben en el acompañamiento en su verdadero lugar. También es necesario para hacerse al "lenguaje personal" del acompañado.

Hay innumerables técnicas de conocimiento propio que pueden ser utilizadas para ayudar al sujeto a conocerse a sí mismo en sus coordenadas personales y para ayudar a las personas a tener una justa y sana autoestima que les permita avanzar sin traumas y a situarse en la vida con autonomía y sencilla normalidad.

La psicología es importante para saber ubicar muchos de los conflictos personales que las personas arrastran por no haber resuelto adecuadamente etapas de maduración personal y que son otros tantos impedimentos para avanzar en la vida del espíritu. La psicología es una ciencia importante también para conocer ciertas astucias, mecanismos y trampas en las que la persona acompañada puede caer.

Pero la psicología no lo es todo y no quiero dejar de poner en guardia acerca del peligro de psicologización que hoy existe en la vida espiritual. Hay demasiados libros, demasiados cursillos de autoestima.

Conocer

los rasgos de personalidad y el "lenguaje" del acompañamiento

miento 
Ciertamente los que ya peinamos algunas canas hemos arrastrado con nosotros un déficit de conocimiento propio y ajeno, y un déficit también de una falta de lectura psicológica de nuestras vidas. Pero no quie-

El acompañamiento espiritual no se puede reducir a psicología momento en que no da más de sí. No puede llenar todo el ámbito del acompañamiento espiritual. Es importante una comprensión recta de la afectividad, de la sexualidad, de la agresividad como impulsos fundamentales de la vida, para saber afrontarla humanamente con sanidad psíquica, pero no todos los datos de la vida pueden ser interpretados psicológicamente ni pueden ser reducidos a pura psicología. La persona en su libertad es más que su personalidad y lo que ha dejado huella humana a lo largo de su historia. Además a cierta edad, los problemas ya no se resuelven fácilmente y lo que hay que hacer es aprender a convivir cordialmente con ellos.

\section{Su historia de fe, su relación con Dios}

Pasamos así al segundo elemento, para mí muy importante, seguramente el más importante. Es indispensable a la hora del acompañamiento, tomar conciencia de cómo se da en el acompañado el proceso de la fe y la búsqueda de la Voluntad de Dios.

Es necesario verificar cuál ha sido la transmisión cristiana. Cómo se ha dado o no, en su vida el encuentro con Jesucristo como Dios personal. Cómo se mantiene hoy esa relación con El en la vida de oración. Qué experiencia hay en ella. Qué constancia hay en ella. Cómo esa oración informa, o no, la vida, y la transforma.

Cómo vivencia el misterio cristiano, el Dios Trinidad, la comuni-

Importante ver que el móvil de su caminar sea Jesús dad, la Iglesia, los sacramentos. Cómo va en su propia vida la adquisición y puesta en práctica de valores y actitudes y el progreso que se da en las virtudes de la vida cristiana. En una palabra: en qué medida el seguimiento de Jesús es el móvil inspirador de los pasos que da. En qué medida la persona es una persona "en camino" y va presidida por la búsqueda de la Voluntad del Padre, no sólo en las grandes encrucijadas de la vida, sino en los pasos más cotidianos.

En este terreno es en el que más se puede encontrar sustento en la teología espiritual. Esta nos da las claves generales de la experiencia y vivencia cristianas. Nos presenta cómo es, cómo se vive, y cómo debe 
ser la experiencia de la fe. Es verdad que el creyente que vive su fe mantiene una relación personal con Dios que no puede ser descrita a priori, sino que se va configurando poco a poco a lo largo de la vida, a medida que se avanza en la escucha de la palabra, en la recepción de la gracia de Dios y en la conformidad a la Voluntad del Señor. En este sentido la santidad cristiana tiene un carácter irrepetible. La teología espiritual nos ayuda a verificar la autenticidad cristiana de la experiencia del creyente.

Otra de las guías necesarias es la lectura de los grandes maestros de oración y de vida espiritual desde los Padres del desierto hasta hoy, pasando por los grandes místicos y ascetas españoles. Es evidente que hay que saberlos leer en clave actual porque si bien sus hallazgos son indiscutibles, sus coordinadas filosóficas y teológicas no son las de Leer a los Padres en clave actual hoy. Pero sin la lectura y meditación de estos grandes autores, sin un nutrirse personalmente de estos alimentos sólidos, me temo que el acompañamiento espiritual no pasará de acompañar un simple "vuelo de gallina". Y la Iglesia de hoy necesita otra cosa. Como decía Teresa de Jesús, la gran Teresa de Avila, "Son menester amigos fuertes de Dios para sostener los muchos flacos". Vivimos tiempos recios para la fe y por ello se hacen necesarios verdaderos amigos recios de Dios capaces de seguir haciendo con Él historia de salvación.

Este acompañamiento de la fe es muy importante en momentos en que la fe parece estar tan poco sostenida por el ambiente y miles de alternativas a la fe intentan seducir el pensamiento y el interés. Este acompañamiento de la fe pasa por un seguir y acompañar el itinerario de la oración, lugar preferente de la relación del acompañado con Dios, donde se va fortaleciendo la vida de fe y donde el Maestro interior, el Espíritu se manifiesta con especial libertad, va dando a conocer sus llamadas y va ayudando a adquirir la sensibilidad que le permitirá reconocer la llamada de Dios, no sólo en los momentos de oración, sino en el acontecer de la vida diaria.

El acompañamiento de la vida de fe va tendiendo a hacer de la persona alguien contemplativo en todas las dimensiones de su vida, capaz de buscar y hallar a Dios en todas las cosas. Condición necesaria para ello será que el que acompaña progrese y vaya por delante en esta misma dirección. 


\section{Su inserción sociocultural}

Un tercer aspecto a considerar es su capacidad de inserción sociocultural, su conocimiento y contacto con la realidad que le rodea, su capacidad de ser ciudadano responsable en este mundo, su postura ante Compro- la cultura circundante. Su disposición a comprometerse responsable y meterse con el entorno creativamente en el entorno. La experiencia del cristiano está siempre situada en la historia, es decir en la cultura, de ahí se sigue la necesidad de asumir la particular historicidad del creyente en sus características culturales y personales, en todas sus expresiones. En el interior mismo de estas dinámicas históricas siempre originales será preciso verificar la relevancia cristiana de cada experiencia.

Somos ciudadanos del mundo y ya el concilio Vaticano II afirmó que "los dolores y los gozos y las angustias y esperanzas de la humanidad son los gozos y esperanzas de la Iglesia" ${ }^{2}$. Cualquier persona que quiera realmente ser considerada como tal tiene que hacer suyas las encrucijadas, los dolores y las búsquedas de los hombres y mujeres de

No descuidar el asentarse con verdad en su tiempo su tiempo. No podemos permitirnos acompañar las vocaciones de los cristianos sin verificar este factor de realismo. ¿Hasta qué punto la persona que acompañamos se asienta con verdad en su entorno, hace suyas las situaciones de la humanidad, se pone en postura simpática (de sunpathos) frente al mundo y es capaz de ofrecer desde donde está una acogida, un compromiso y una entrega real en el entorno movida desde el amor de Jesús por el mundo y por los hombres y mujeres en él?

Dios está en la vida y le respondemos en la vida. Decíamos en el apartado anterior que hay que verificar hasta qué punto la oración va transformando la vida. Deberíamos decir aquí también que la plenitud del compromiso con el entorno, con el mundo es el reconocimiento y la adoración del Dios vivo presente en él.

\section{Espiritualidad y discernimiento}

Ya he dicho algo de esto al hablar del tema del acompañamiento de la fe. La persona que va madurando cristianamente tiene que ir adquiriendo una sensibilidad especial, una capacidad de discernir, de

2 Vaticano II, Gaudium et spes. 
detectar de dónde vienen sus movimientos para identificarse plenamente con los movimientos del Espíritu y dejar caer todos los demás.

El discernimiento supone una capacidad de integración de su vida en un todo coherente y la adquisición de un juicio objetivo y recto ante los problemas de la vida y una sensibilidad espiritual que le permita distinguir entre los datos de la vida que llegan, aquellos que conducen al progresar evangélico y al seguimiento más cercano de Jesús.

\section{Formar para acompañar}

Cualquier diócesis o Instituto o Congregación necesita por tanto plantearse hoy la formación de acompañantes, puesto que no hay muchas personas que hoy estén experimentadas y habilitadas para ello

La formación ha de incluir los ámbitos que he enumerado en los apartados anteriores, pero ha de ser una formación teórica y práctica a la vez. Teórica que favorezca una formación del pensamiento y esto se hace con clases, con lecturas y sobre todo con una asimilación personal de ambas contrastada con la propia experiencia, de manera que la personas que se forman lleguen a hacer suyo un esquema personal y sometan a revisión a medida que van avanzando en el estudio su propia experiencia personal.

Ha de ser práctica por otra parte. La entrevista, el encuentro interpersonal, es una asignatura de mucha importancia en el acompañamiento espiritual.

El encuentro personal es un factor esencial en el acompañamiento. Este encuentro personal tiene unas características especiales. Es fraternal pero no es la experiencia de una amistad de igual a igual. Es un encuentro que no reproduce las relaciones materno o paternofiliales. El encuentro personal amigable es importante, mantener el clima amistoso es esencial, pero sin condicionar la claridad y la firmeza de la persona que acompaña y sin hipotecar su libertad ni la del sujeto acompañado.

Entrenarse en el arte de escuchar puede parecer sencillo y tiene su dificultad. Nuestra sociedad nos capacita cada vez más para desarrollar la visión y no la escucha. Y he aquí que la escucha a todos los niveles es esencial. Escucha de lo que se nos dice, y de lo que no se nos dice Entrenarse en el arte de escuchar pero se nos insinúa tímidamente. Escucha de los mensajes internos a lo que se nos está diciendo; escucha de la persona en su lenguaje total,

Formación teórica que alimente el pensamiento $y$ práctica 
verbal y no verbal. Escucha para comprender bien y que conlleva la renuncia constante a dar soluciones, recetas, consejos, a hablar mucho, a tener enseguida a mano soluciones prácticas. Escucha paciente que deja la iniciativa siempre a la persona y que tan sólo interviene para ayudar a avanzar. Lo que importa no es que el acompañado alcance la meta rápidamente sino que se encuentre con alguien, una presencia que sostiene y acompaña su camino y la va fortaleciendo para ir adelante.

Somos personas muy tendentes a recorrer más camino del que el otro presenta, a adelantarnos a su ritmo e ir más rápido que lo que él mismo ve. Y esto no sólo no ayuda sino que es perjudicial. Somos además tendentes a dar consejos, a ofrecer soluciones rápidas, a dar recetas, a hablar y decir nuestras opiniones. Nada de esto es conveniente. La escucha del otro en toda su verdad es lo verdaderamente esencial.

Acompanante, verdadero contemplativo, que orienta tras comprender Lo he dicho ya en otro sentido, pero el que acompaña ha de ser un verdadero contemplativo, que toma conciencia, escucha, acoge y sólo a partir de haber comprendido bien aventura su palabra. Para ello son convenientes las preguntas clarificadoras que establecen la verdad de lo que se ha escuchado; las preguntas abiertas que permiten al otro definirse. No preguntas inquisitoriales ni curiosas, ni excesivas, no preguntas que traen encerrada previamente la solución. Preguntas que ayudan a hacer mejor el camino de la libertad y que clarifican los mensajes que el acompañado transmite en la entrevista.

La entrevista supone encuentro humano, pero supone también una experiencia, un entrenamiento, un rodaje. Conviene ejercitarse en ella en algún curso dedicado a la entrevista, para ir adquiriendo destrezas propias de la relación humana que no se oponen en manera alguna a una conducción verdaderamente espiritual.

\section{Quién puede acompañar}

Otro aspecto importante para la formación es la persona misma que acompaña. No se exige de él que sea una persona perfecta, de ningún modo, pero sí ha de ser una persona relativamente madura, que haya tenido tiempo de recorrer sus propias etapas de maduración humana y espiritual.

Una persona comprometida con la vida y con la sociedad. Lleno de interés por la vida y por el plan de Dios sobre sus hijos e hijas. Una 
persona a quien no le sea indiferente el crecimiento de las personas, que sepa esperar con esperanza activa los pasos lentos que cada persona ha de dar para superar sus dificultades, y por ello se haga capaz de ser impulsora a través de ellas de una sociedad nueva.

Una persona integradora, que aunque toca todos los aspectos de la vida del otro, edad, afectividad, relaciones, inteligencia, equilibrio, madurez humana, capacidad de compromiso, siempre mira a la unificación de todos estos aspectos en torno al sentido último de la vida, al estado de vida, a la fidelidad constante a la voluntad de Dios.

Una persona convencida de la singularidad cristiana de la persona que le es confiada, destinataria de una llamada particular del Señor. Esto reclama un esfuerzo constante de atención para lograr discernir el auténtico hallazgo de algo original, de algo que no puede reducirse a lo conocido, a las teorías de los libros a esquemas universales. El que acompaña tiene por misión discernir de qué modo concreto el sujeto es llamado a ser memoria de Jesús, en relación con su estado de vida y su ministerio eclesial.

Una persona fundamentalmente esperanzada, a la que no echen para atrás los fracasos inevitables en la lucha, que no se asombre de las infinitas debilidades humanas. Experimentado en el sufrimiento normal de la vida pero no vencida por él. Una persona confiada en el proyecto de amor que Dios tiene para cada uno de sus hijos y del que en su fidelidad no se vuelve atrás a pesar de las infinitas vacilaciones que éstos muestran.

Una persona revestida por el amor. Haber amado y haber sido amado es una condición indispensable para seguir amando hasta el final. Sólo desde el amor verdadero se puede acompañar, porque el hacerse compañero de camino supone una entrega amorosa y desinteresada.

Supone también ser un conocedor de la lucha de la vida. No hay seguimiento ni camino espiritual que no pase por el abrazar la cruz de cada día. Para crecer hay que luchar y hacer de los combates de la vida ocasión para ir superando los peldaños que conducen a la madurez en el espíritu, cima de la madurez humana.

Supone ser una persona que sabe que su relación con el acompañado es asimétrica pero es experimentada en el difícil arte de la amistad que se entrega, sin falsas concesiones a una aparente camaradería. 
Empatía, Una amistad madura que mira siempre al otro con empatía, con toda

342 manteniendo la distancia que da perspectiva simpatía, pero que sabe conservar la distancia necesaria que requiere el mantener a lo largo de los contactos un gran sentido de su dignidad.

Es una persona experimentada en pecados y fracasos pero con conciencia de salvado. Nadie como él ha debido experimentar la radical debilidad de la propia vida humana. Por ello no se escandalizará jamás de los pecados de aquél que acompaña, si los conoce sea o no ministro de reconciliación, ni se asustará de sus pequeños o grandes fracasos. Conoce por experiencia las propias dificultades y conoce sobre todo a Aquél que está de nuestra parte para ayudarnos a vencer y en él confía para sí y para los otros.

La persona que acompaña es una persona suficientemente contemplativa y vulnerable para dejarse alcanzar de la realidad del otro. No tan vulnerable que se hunda con los hundimientos del acompañado pero sí capaz de hacerse idea de sus sufrimientos y de captar sus sentimientos, para ayudarle a liberarse.

El acompañante es finalmente un testigo cualificado de lo que sucede a aquél a quien acompaña y que se mantiene en sintonía con el Espíritu que le conduce. Para ello es una persona de oración que pasa por la oración la búsqueda vocacional de su acompañante y que recurre a la oración en los inevitables recodos e interrogantes e impasses del camino.

\section{Conclusión: a modo de resumen}

En el camino de nuestra vocación cristiana hoy necesitamos con urgencia de la ayuda de otros hermanos y hermanas que nos ayuden no sólo a descubrir nuestra vocación específica sino a descubrir todos los matices y esplendor de la vocación que cada persona tiene en su transcurso por esta vida, vocación que Dios nos ha dado pero vocación a la que nosotros hemos de ir descubriendo y responder.

Esa ayuda que nos ofrecen es la persona que acompaña, un arte de hacer camino con los otros y de ayudarles a recorrer con libertad el propio camino, de ir hacia delante y hacia adentro cada vez con mayor profundidad.

Para poder ayudar a otros, las personas que quieren crecer en el arte del acompañamiento han de hacer su esfuerzo formativo, esfuerzo 
que supone estudio y lectura, esfuerzo que supone asimilación y confrontación con la propia experiencia, esfuerzo que supone también adiestramiento y práctica, y sobre todo que exige una gran autenticidad personal y una cierta experiencia de haber sido acompañado.

No hay perfiles unívocos en la personas capaces de acompañar pero si han de ser personas de honda densidad humana y que le vean sentido y sean capaces de mirar con cariño a quienes acompañan y se sientan vivir con sentido este horizonte apostólico.

Hay algunos acompañantes que nacen. Personas especialmente dotadas para la relación de ayuda y que tienen una honda vivencia espiritual. Pero estas personas también se hacen y pueden multiplicarse creando un ambiente apropiado para ello y deben apoyarse en nuestras instituciones creando programas, seminarios, encuentros de acompañamiento, grupos de intercambio que ayuden a crecer.

Vamos a terminar con una evocación: es el diálogo de Jesús junto al pozo de la samaritana. Un texto que conocemos de sobra.

No hay mejor ejemplo práctico que este encuentro de acompañamiento. Jesús es el acompañante verdadero que sale al encuentro de la mujer. En esta entrevista/encuentro se dan las condiciones necesarias de diálogo en verdad que hacen que la persona avance de círculo en círculo hasta la maduración de su deseo que culmina en el encuentro con el Mesías.

Os invito a leerlo muchas veces y a descubrir en él vuestra personal vocación al acompañamiento y a dejaros convertir con él en personas que hacen avanzar a los otros hasta la profundidad de su propia vocación y hacia su plenitud. 